\title{
Análise dos componentes gráficos e informacionais das embalagens de biscoitos
}

\section{An analysis of the graphic and informational components of biscuit packaging}

Ester Costa dos Santos, Érika Veras, David Guilhon, Carmem Helena Ribeiro Maciel Maciel e Camila Vieira dos Santos

Embalagem, elementos gráficos, análise.

\begin{abstract}
Este artigo visa a análise e a percepção dos elementos gráficos que compõem embalagens de biscoitos vistos nas prateleiras dos mercados de São Luís do Maranhão, fazendo um comparativo entre eles e apontando os padrões que eles possuem, como: cores, ilustrações, texturas e tipografias. A metodologia utilizada para os comparativos entre embalagens foi a do autor Mijksenaar (1997) e através dela elaboraramse tabelas contendo as informações e características de cada embalagem de biscoito escolhida.
\end{abstract}

Packaging, graphic elements, analysis.

This article aims to analyze and perceive the graphic elements that make up packages of cookies seen on the shelves of the markets of São Luís do Maranhão, making a comparison between them and pointing out the patterns they have, such as: colors, illustrations, textures and typographies. The methodology used for comparisons between packages will be that of the author Mijksenaar (1997) and through it tables were elaborated containing the information and characteristics of each chosen cookie package.

\section{Introdução}

O mercado do design de embalagens desenvolveu-se muito ao longo dos anos, trazendo diferentes propostas, formatos, materiais e identidades visuais voltadas para cada público-alvo, principalmente quando se trata de embalagem para produtos alimentícios. Porém, alguns pacotes não são tão atrativos ou condizentes com a proposta da marca ou do alimento que tentam vender para o consumidor. É necessário um estudo prévio ao desenvolvimento destas embalagens, para que haja uma comunicação clara e chamativa aos olhos do público a ser atingido.

Ampliando o olhar na análise das embalagens de alimentos, a indústria dos biscoitos é uma das maiores do ramo, atraindo principalmente as crianças, que são grandes consumidoras deste tipo de produto. Tendo em vista esse nicho de consumidores, as marcas buscam cada vez mais trazer embalagens animadas e coloridas para chamar a atenção das crianças e assim influenciar nas compras.

Além de buscar entender os elementos gráficos destas embalagens, ao longo do trabalho também foram verificados os aspectos informacionais, visando compreender se dados Curitiba | Brazil | 2021 
importantes, como lista de ingredientes e alertas de restrições alimentares para pessoas alérgicas, estão sendo bem compreendidos por seus potenciais compradores. "O consumidor vê as embalagens de maneira racional e emocional. Primeiro, ela compõe a identidade e a personalidade do produto e permite a projeção de valores e sensações" (Pellegrino, 2004, p. 88)

Foi feita a análise de produto da embalagem, utilizando a metodologia Mijksenaar (1997), a fim de categorizar e entender a distribuição das informações dispostas, assim como a hierarquia visual.

\section{Fundamentação}

\section{Embalagem e suas funções}

Para Santos \& Castro (1998), as embalagens servem como meio organizacional na hierarquização das informações que desejam ser comunicadas ao consumidor. Essas informações, posteriormente, se tornam decisões tomadas pelo futuro usuário daquele produto. Tal característica deve ser levada em conta no momento de desenvolvimento da embalagem, pois, destacar os pontos principais do produto pode tanto induzir a compra dele, quanto alertar o usuário dos prováveis riscos que aquele produto oferece. No caso de alimentos, advertir que os mesmos contêm lactose, amendoim ou açúcares, pode evitar um problema futuro para um portador de alergia.

Conforme os autores, é preciso estar bem atento para que todas as informações sejam passadas de forma clara ao leitor. Wright (1999) e Spinillo (2000) sugerem formas de obter esse diálogo claro entre marca e comprador, como por exemplo, o uso da voz ativa para enfatizar e assegurar que ao ler tais informações aquele usuário não fique com nenhuma dúvida e tenha a melhor experiência com o produto. Estas preocupações organizacionais e informativas, mescladas com uma boa identidade visual, favorecem a comunicação e a atração do olhar do cliente para o produto que a embalagem contém.

\section{Elementos visuais traduzindo o produto através da embalagem}

Strunck (1989) disse que, ao analisar o nosso meio social competitivo para uma ideia ser posicionada, esta precisa ser conhecida pelo público para atingir seu resultado. Ela precisa de informações visuais que a tornem memoráveis e manifestem sua qualidade. Elementos visuais ergonômicos e de usabilidade têm grande peso na decisão do consumidor.

Por isso, um design bem desenvolvido, pensado nas necessidades do cliente, na parte visual da embalagem e sua ergonomia, pode se tornar um grande diferencial na competição da prateleira de um supermercado, visto que algumas marcas não têm tais preocupações.

Nóbrega, Cunha \& César (2014, p.2) e Stewart (2009) dizem que a cor pode parecer inicialmente como um meio de promover a identidade de marca e fixar a imagem. E assim o é. Porém, aplicações em embalagens trazem muitas mensagens codificadas por cores associadas às categorias particulares de produto. Isso resulta, muitas vezes, na cópia da cor dominante adotada pelo líder da marca do setor. 
Logo, com o intuito de instigar o comprador a sentir as sensações que aquele biscoito pode causar, antes mesmo que ele de fato experimente, as marcas buscam passar essas sensações através das identidades visuais dos pacotes, seja trazendo texturas, representações de recheios, cores referentes ao sabor, entre diversas estratégias visuais que captem ao máximo o que é proposto pela bolacha em questão.

\section{Tipografia e cores}

Sobre as tipografias utilizadas em embalagens, pode-se destacar como as marcas utilizam este recurso para passar mensagens sensoriais e sabores dos biscoitos através dos elementos tipográficos. O tipo da fonte e o peso da mesma podem levar o consumidor à diferenciação entre um produto de sabor doce, salgado ou amargo, como aponta Velasco et al (2016), que afirma que sabores mais doces são comumente expressados por formatos redondos e os sabores ácidos são representados por formas angulares.

Quanto às cores, as mesmas podem ser escolhidas para compor embalagens com o objetivo de fazer uma relação entre sabor do biscoito com a cor do pacote. Mai, Symmank \& SeebergElverfeldt (2016) apontam que cores pálidas e sóbrias, geralmente fazem o consumidor associar a produtos saudáveis. Tijssen et al. (2017) alegam que efeitos da cor de embalagens são mais intensas para expectativas sensoriais do que para percepções de sabor, tendo a combinação de elementos de cor (tom, brilho e/ou saturação) tornando os pacotes mais atrativos.

\section{Metodologia}

A metodologia aplicada nesta pesquisa foi pautada no método de Mijksenaar (1997), que apresentou uma adaptação das variáveis de Bertin para o design. Neste método há uma divisão de três etapas, neste caso, foram utilizadas apenas as de diferenciação e hierarquia. Cada uma delas foi apresentada em forma de quadro para análise das embalagens.

Figura 1: Adaptação das variáveis visuais de Bertin para o design. Fonte: acervo pessoal

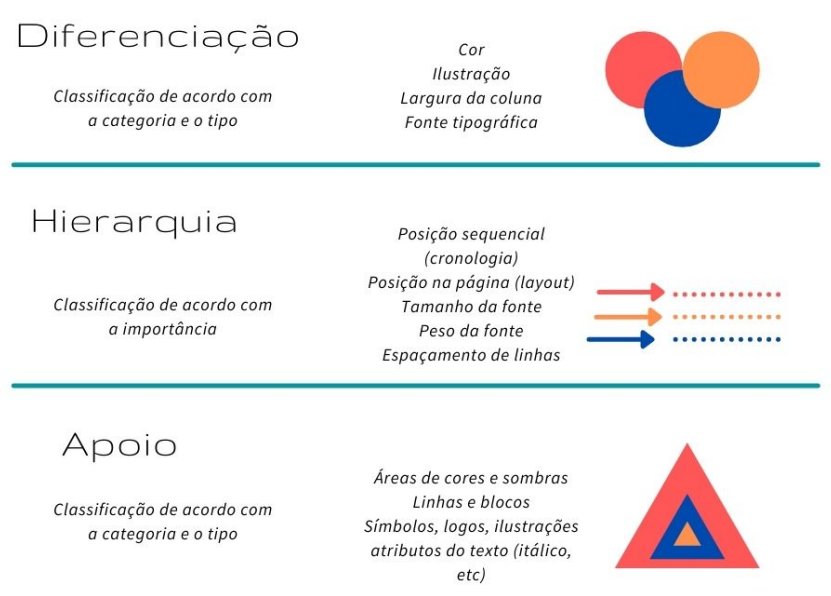




\section{Resultados e discussões}

Nesta etapa foram avaliadas as embalagens de biscoitos escolhidas através da metodologia de Mijksenaar (1997), a partir de alguns tópicos da tabela, como por exemplo o de diferenciação (cor e ilustrações) e hierarquia (peso da fonte, tamanho da fonte e posição da página).

\section{Objetos de estudo}

Foram analisados três grupos de biscoitos: os recheados, os fitness/saudáveis e os que são voltados para o público infantil.

\section{Etapa de diferenciação (Cor)}

O quadro 1 apresenta as amostras dos produtos na etapa de diferenciação.

Quadro 1: Etapa de diferenciação. Fonte: Elaborada pelos autores

Cor


Azul

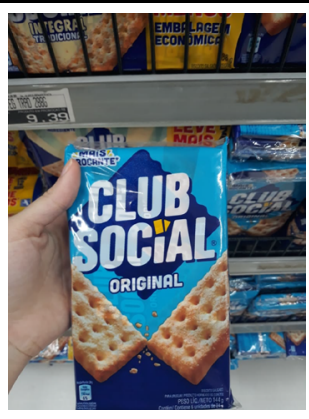

Azul e branco
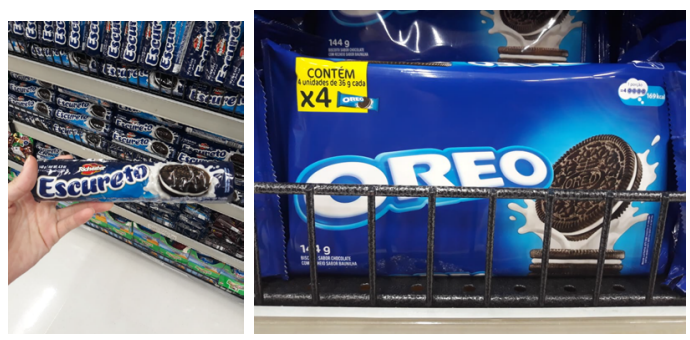

Azul, branco e vermelho
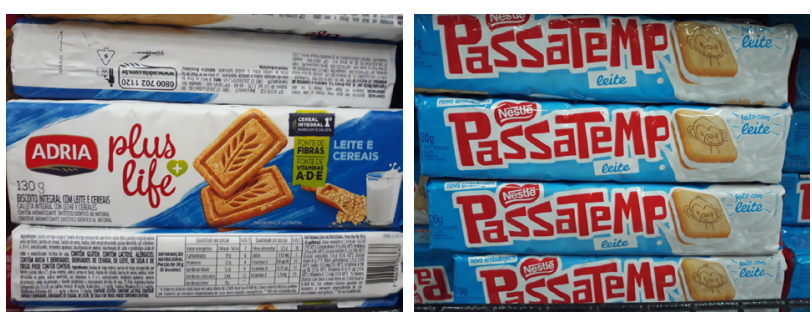

Marrom, verde e amarelo
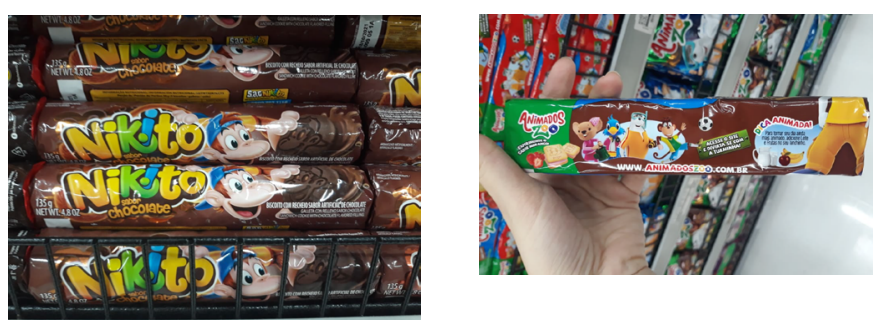

Através da análise das imagens, percebeu-se que a cor azul está muito presente na maioria das embalagens apresentadas, principalmente nos biscoitos saudáveis e nos recheados.

Outras cores muito encontradas em embalagens de biscoitos saudáveis são as cores amarela e vermelha. Analisando o nicho de biscoitos infantis, percebeu-se a presença de tons em marrom, verde e amarelo na mesma embalagem.

\section{Etapa de diferenciação (Imagem e ilustração)}

O quadro 2 apresenta as amostras dos produtos na etapa de diferenciação. 
Quadro 2: Etapa de diferenciação (imagem e ilustração). Fonte: Elaborada pelos autores.

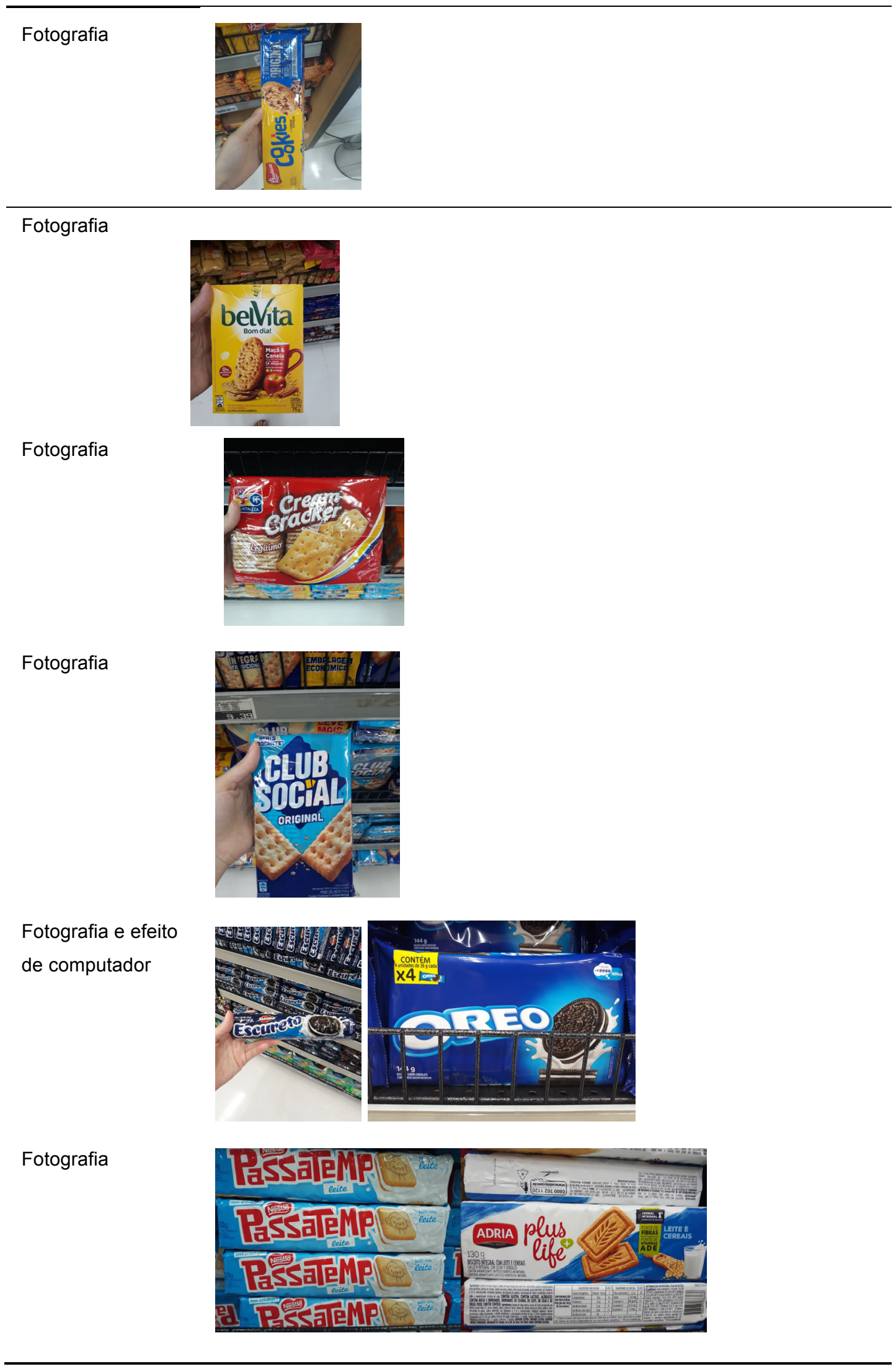


Marrom, verde e

amarelo

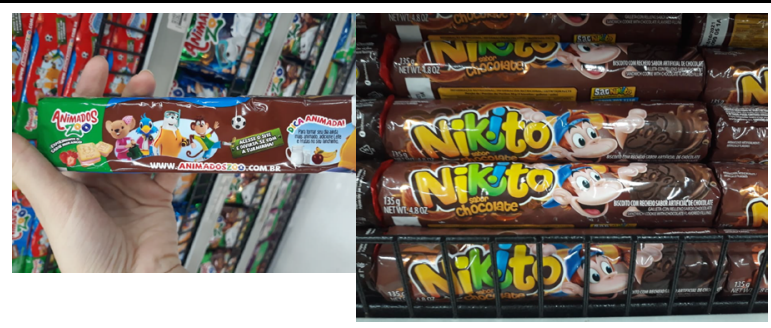

Através da análise das imagens, percebeu-se que a maioria das embalagens opta por utilizar fotografias e imagens manipuladas por computador, na maioria das vezes para representar as texturas como recheios, enquanto as embalagens que optam pelo uso da ilustração são aquelas voltadas para o público infantil.

\section{Hierarquização (peso da fonte/tamanho da fonte)}

O quadro 3 apresenta as amostras dos produtos na etapa de diferenciação.

Quadro 3: Etapa de hierarquização. Fonte: Elaborada pelos autores.

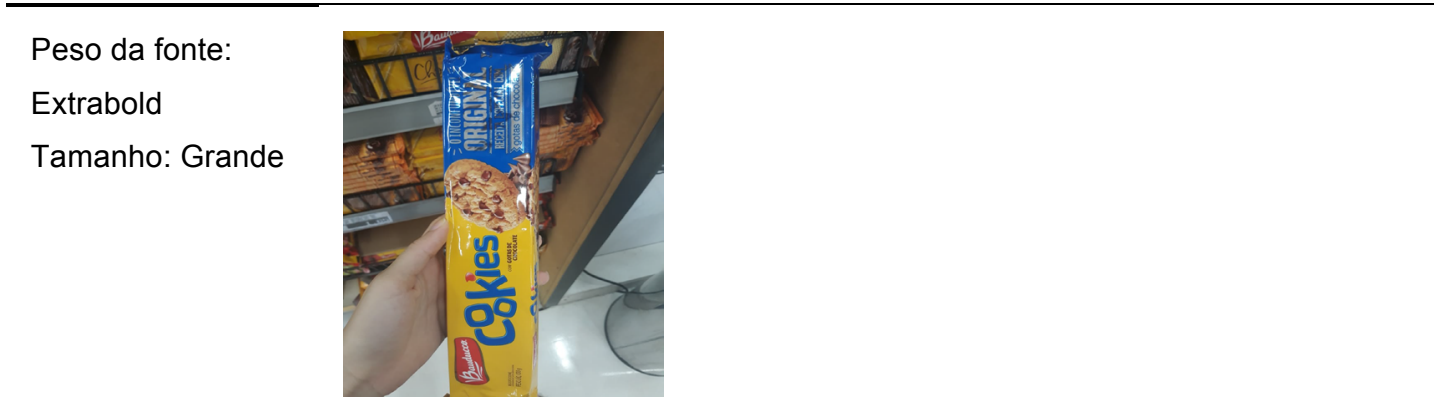

Peso da fonte:

Semibold

Tamanho da fonte:

Médio
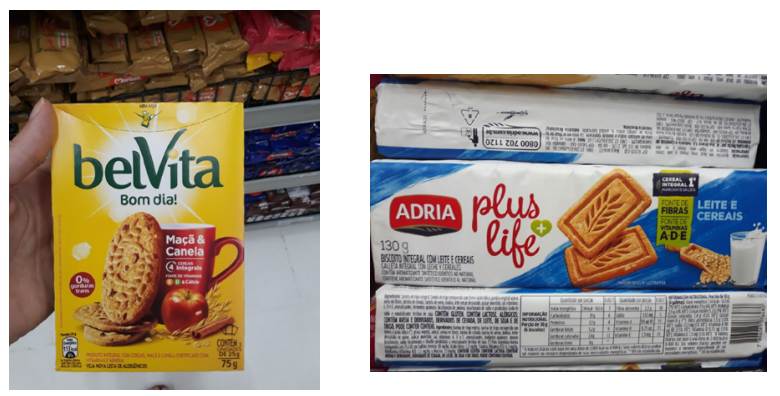

Peso da fonte:

Black

Tamanho da fonte:

Grande
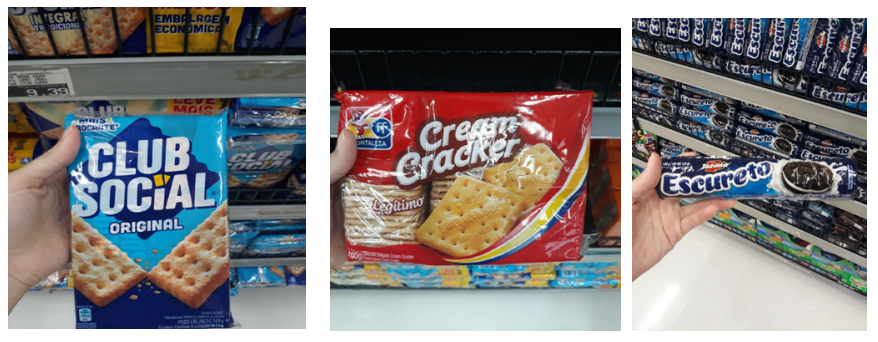

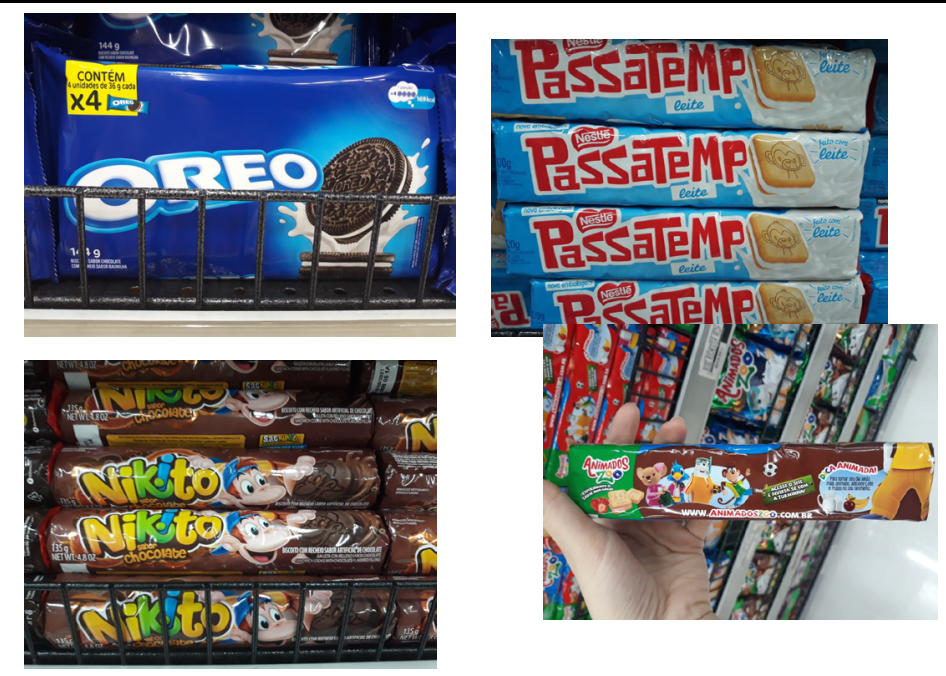

Ao analisar os elementos de peso e tamanho da fonte, notou-se a presença, em muitas embalagens, da fonte Black em tamanho grande, captando a atenção do consumidor para o nome do biscoito. Já no nicho de biscoitos saudáveis, o uso de fontes com peso Semibold e tamanho médio são comumente encontrados.

\section{Considerações finais}

Com base nos dados apresentados, foi possível perceber elementos em comum em algumas marcas que seguem o mesmo nicho de mercado. Estas características podem ser consideradas como uma forma de identificação aos olhos do consumidor, ao buscar produtos daquele segmento em prateleiras do supermercado. "A identidade conceitual da empresa ou corporativa é o conjunto de características internas que permitem identificar e diferenciar uma empresa de outra" afirma Vasquéz (2007, p. 204). Porém esses elementos visuais parecidos podem ser interpretados como uma forma de convencimento do consumidor de que aquele produto, por possuir a embalagem similar à de outro, possui o mesmo sabor. Tais itens gráficos podem até confundir alguns compradores.

Durante a busca por embalagens para a análise houve uma dificuldade em achar maior variedade entre os mercados, devido ao momento de pandemia atual, visto que este cenário dificulta a distribuição da mercadoria e compromete a variedade de produtos nas prateleiras.

Apesar da pouca variedade para a comparação dos produtos, foi possível alcançar o objetivo de criar um parâmetro de comparação entre as embalagens analisadas.

\section{Referências}

Karsaklian, E. (2000) Comportamento do consumidor. São Paulo: Atlas.

Mai, R; Symmanck, C; Seeberg E. (2016). Light and Pale Colors in Food Packaging: When Does This Package Cue Signal Superior Healthiness or Inferior Tastiness? In: Journal of Retailing. 
Mestriner, F. (2001). Design de embalagem: curso básico. São Paulo: Makron Books.

Moura, R. e Banzato, J. (2000). Embalagem, unitização e conteinerização. 3 ed. São Paulo: IMAM.

Nóbrega, C; Cunha, R; César, S. (2016). O food design como ferramenta de criação-análise do universo de biscoitos recheados para atrair o público consumidor infantil. In: VII World Congress on Communication and Arts 101. April 20 - 23, Vila Real, PORTUGAL.

Nogueira, J et al. (2015). A embalagem como componente estratégico do marketing para lançamento do produto. caderno profissional de marketing. In: CPMark - Caderno Profissional de Marketing - UNIMEP. v.3, n.1.

Samara, T. (2007). Grid: construção e desconstrução. São Paulo: Cosac Naify.

Santos, R. e Castro, V. (1998). Uma proposição sistêmica para o desenvolvimento de embalagens. In: RAE - Revista de Administração de Empresas. São Paulo.

Scanavino, D; CAMPO, G. (2016). Design de embalagem e visualização de dados: uma perspectiva do grid tipográfico. In: XX Congreso de la Sociedad Iberoamericana de Gráfica Digital [=Blucher Design Proceedings, v.3 n.1]. São Paulo: Blucher.

Spinillo, C. (2000). An analytical approach to procedural pictorial sequences. Londres.

Steawart, B. (2009). Estratégias de design de embalagem. Tradução Bill Stewart. 2. ed. São Paulo: Bluncher, v. 5. Tradução de: Packaging design strategies.

Strunck, G. (1989). Identidade Visual - A direção do Olhar. Rio de Janeiro.

Tijseen, I. et al. (2017). Why a 'light'product package should not be light blue: Effects of package colour on perceived healthiness and attractiveness of sugar-and fat-reduced products. In: In: Food Quality and Preference. Volume 59, Pages 46-58.

Vásquez, R. (2007). Identidade de marca, gestão e comunicação. In: Organicom, v. 4. N 7.

Velasco, C. et al. (2016). Crossmodal correspondences between taste and shape, and their implications for product packaging: A review. Food Quality and Preference,

Wright, P. (1999). Printed instructions: can research make a difference? London: Taylor \& Francis.

\section{Sobre os autores}

Ester Costa dos Santos,Bac. Universidade Ceuma, Brasil. esterhihu@gmail.com

Carmem Helena Ribeiro Maciel, Bac. Universidade Ceuma, Brasil.

carmemribeiro884@gmailcom

Camila dos Santos Vieira, Bac. Universidade Ceuma, Brasil. Camiladsv3@gmail.com

David Guilhon, Universidade Ceuma,Me. Brasil. dvdguilhon@gmail.com

Érika Veras de Castro, Universidade Ceuma,Me. Brasil. erikaufma@gmail.com 